\title{
Knowledge on Food Safety and Food-Handling Practices of Street Food Vendors in Ejisu-Juaben Municipality of Ghana
}

\author{
Raymond Addo-Tham, ${ }^{1}$ Emmanuel Appiah-Brempong, ${ }^{2}$ Hasehni Vampere $\mathbb{D},{ }^{2}$ \\ Emmanuel Acquah-Gyan, ${ }^{2}$ and Adjei Gyimah Akwasi ${ }^{2}$ \\ ${ }^{1}$ University Hospital, Kwame Nkrumah University of Science and Technology, Kumasi +233 , Ghana \\ ${ }^{2}$ School of Public Health, Kwame Nkrumah University of Science and Technology, Kumasi +233, Ghana \\ Correspondence should be addressed to Hasehni Vampere; vamperehassan@gmail.com
}

Received 22 July 2019; Revised 18 January 2020; Accepted 24 February 2020; Published 17 March 2020

Academic Editor: Guang-Hui Dong

Copyright ( 2020 Raymond Addo-Tham et al. This is an open access article distributed under the Creative Commons Attribution License, which permits unrestricted use, distribution, and reproduction in any medium, provided the original work is properly cited.

\begin{abstract}
Street foods have become a major source of cooked food for most households and individuals in many developing countries including Ghana. However, the rising concern about food-borne illness has questioned the knowledge of the street food vendors to constitute safety practices for food handling. This study assessed the knowledge of street food vendors on food safety and foodhandling practices in the Ejisu-Juaben Municipality of Ghana. The study used a cross-sectional mixed approach involving 340 participants selected by simple random sampling. A structured questionnaire and an observational checklist were used to collect data and analyzed using STATA version 12 . The results indicated that $98.8 \%$ of the food vendors had good knowledge on food safety and handling. The knowledge on food safety was associated with training ( $p$ value $\leq 0.011)$, license status ( $p$ value $\leq 0.002)$, marital status ( $p$ value $<0.001$ ), and religion ( $p$ value $\leq 0.038$ ). Good food-handling practices were associated with training ( $p$ value $\leq 0.001)$ and license $(p$ value $\leq 0.002)$ and not their educational levels. The study found training of food vendors as the most effective way to increase knowledge on food safety and enhance food-handling practices. The study recommended for collaborations of municipal assemblies with other agencies to strengthen, sustain, and organize regular training programs for new entrants and existing food vendors as well as retraining of trainers to equip them adequately with knowledge and skills to enable them effectively facilitate training programs for food vendors.
\end{abstract}

\section{Introduction}

Street foods have now become a major source of food for most homes and individuals especially in developing countries [1]. It is consumed by about 2.5 billion people worldwide on daily basis [2]. This is because most people spend less time at their home due to busy work schedules and therefore depend on street foods [3]. Street foods are relatively inexpensive, easily accessible, and offer a variety of meals to consumers [4]. The street food industry is therefore growing at a very fast rate worldwide [5]. It has become a source of employment and income for individuals and homes. Increasing unemployment rates and poverty are also major factors that influence people to venture into street food business [6] because it requires minimal capital to set up [7].
According to the WHO [8], globally, one out of every ten persons contract food-borne illnesses. Over ninety-one million people including Africa acquire food-borne illnesses every year with resultant deaths of about one hundred and thirty seven thousand. In Ghana, one out of every 40 people is infected with a food-borne disease annually [9] and results in about sixty five thousand deaths [1]. It is also estimated that the government spends about US $\$ 69,000,000.00$ on food-borne illnesses $[4,9]$.

Street foods have been linked with numerous food-borne illnesses and food poisoning outbreaks $[10,11]$. This has led to a growing public health concern on food safety [12]. The activities of street food vendors are therefore regulated in many countries. In Ghana, the Food and Drugs Authority under the Ministry of Health ensures that food available for 
public consumption is safe. Their effort is complemented by the Ghana Standards Authority, the Ministry of Food and Agriculture, the Veterinary services, the Ghana Tourism Board, and others. The metropolitan, municipal, and district assemblies have also been mandated to enforce street food safety standards [13]. The Environmental Health Department of these assemblies ensures that food vendors are medically screened and certified and are also trained periodically on food hygiene and sanitation $[4,9]$. The World Health Organization has recommended five strategies to ensure food safety. These include separating raw and cooked food, using safe water and raw materials, cooking thoroughly, keeping food at safe temperatures, and keeping clean. These strategies have been adopted by several training programs for street food vendors especially in developing countries [14]. Despite all these efforts, there are, however, gaps in the operations of food safety regulatory institutions and the laws governing food safety, knowledge of food vendors on safety food practices, and the food-handling practices of food vendors [15]. This has led to substandard food safety practices by food vendors [11]. In view of these problems, this study aimed at assessing the knowledge on food safety and food-handling practices of street food vendors to ensure food safety. It also sought to determine the factors which can influence the knowledge on food safety and food-handling practices of food vendors in Ejisu-Juaben Municipality, Ghana.

\section{Materials and Methods}

2.1. Study Setting. Ejisu-Juaben municipality is in the Ashanti Region of Ghana. It is found within Latitudes $1^{\circ} 15^{\prime}$ north and $1^{\circ} 45^{\prime}$ north of the equator and longitude $6^{\circ} 15^{\prime}$ west and $7^{\circ} 00$ west of the Greenwich Meridian. As at 2010, the municipal has a population size of 143,762 in ninety-one communities and about three thousand (3000) registered street food vendors [16]. The majority of the households (61.8\%) depends on borehole water for domestic activities. Open dumping is the mechanism for disposing solid wastes by the majority (65\%) of the residents, while $43.4 \%, 34.9 \%$, and $10.2 \%$, respectively, disposed liquid waste unto the streets, compounds, and gutters [16]. Most households $(48.8 \%)$ depend on public toilet facilities which are inadequate and poorly maintained, and therefore waste management is an area of major concern to the municipality [17].

The study was conducted in the two most urbanized communities (Ejisu and Juaben) where activities of street food vendors are higher.

2.2. Study Design and Approach. The study adopted a crosssectional design and utilized a mixed approach to assess the knowledge and food safety practices of food vendors. This method was used to objectively quantify knowledge on food safety and also observe food-handling practices among participants.

2.3. Study Population. The target population consisted of all food vendors in the municipality. Stationary street food vendors in Ejisu and Juaben communities constituted our sampling frame. The stationary food vendors have a permanent location and are therefore easily tracked and monitored. Therefore, all stationary street food vendors within the sampling frame were given equal chance of being part of the study. Mobile food vendors (hawkers) within the sampling frame were excluded from the study. Their mobile nature could have made tracing for clarification of responses and observation of their practices challenging.

2.4. Sampling and Sample Size. Study participants were obtained using a simple random sampling method. All stationary food vendors within the sampling frame were given an equal chance of selecting a "YES" or a "NO" from a ballot box. Those who picked "YES" were enrolled into the study. Other vendors unwilling to participate in the study were, however, excluded.

\subsection{Formula}

$n=Z^{2}(p q) / d^{2}[18]$

$n=$ the required sample size

$Z=Z$ score at $95 \%$ confidence level with a standard value of 1.96

$p=$ estimated prevalence $(0.5)$

$q=1-p$

$d=$ margin of error $=0.05$

$n=(1.96)^{2}\left(0.5^{*} 0.5\right) /(0.05)^{2}$

$n=384.16$

\subsection{Applying Correction for a Finite Population}

$n=n / 1+(n-1 / N)$

$n^{\circ}=$ new sample size

$n=$ the calculated sample size for the infinite population

$N=$ population size

$n=384 / 1+(384-1 / 3000)$

$n=340$.

Ejisu and Juaben had 500 and 152 registered food vendors, respectively, according to the registry of food vendors in the municipality in 2016. The proportional sample size for each town was calculated as follows:

Ejisu: $(500 / 652) * 340=261$

Juaben: $(152 / 652)^{*} 340=79$

2.7. Data Collection Techniques and Tools. A structured questionnaire and an observational checklist were used to collect data for the study. These instruments were developed by the researchers based on the [19] essential requirements for street food vendors. The questionnaire was used for collecting data on the sociodemographic characteristics and knowledge on food safety among participants. In assessing knowledge, a mark was awarded for every correct answer 
and zero point for incorrect answers or unanswered questions. The total marks were expressed as a percentage. A score more than or equal to $50 \%$ was graded as good, and scores less than $50 \%$ was graded as poor.

An observational checklist was also used to compile information on food-handling practices of the participants during serving. These practices were also scored and graded. A mark was awarded for every standard practice and zero for every unhygienic practice. The total marks in each section was expressed as a percentage and graded in the same way as the knowledge score. A nonparticipant observation was adopted by researchers.

2.8. Validity and Reliability. To ensure validity, the data collection tools were subjected to the approval of the Committee of Human Research, Publication and Ethics of Kwame Nkrumah University of Science and Technology, for content validity. Pretesting of the questionnaires and the observation checklist was done among 30 street food vendors in the Bosomtwe district using the local language (Asante Twi) since most food vendors cannot read and understand English well. The pretest was conducted by the principal researcher (first author) supported by the other coauthors. This enabled the researchers to fine-tune the questions and the checklist, making them clearer and more comprehensible to ensure reliability.

2.9. Limitations of the Study. Researchers' direct observation of food vendors could have influenced food safety practices of respondents however creating a Hawthorne effect. Participants recalling information such as how long they have been operating and their most recent participation in a training program creates room for recall bias. Again, because there were no records to verify responses of participants, researchers assumed that participants' responses to these questions were accurate. Also, no causal conclusions were made from associations between variables since this was a cross-sectional study. These limitations were managed by not notifying food vendors before observation starts even though consent was sought on previous days before observation on a different day. Participants were also allowed a good time to try to recall previous information to minimize recall bias. The researchers also took time to explain the questions accurately in the local language to the participants so that participants can provide accurate answers as possible.

2.10. Data Analysis Method. Data were entered into Microsoft Excel 2013 edition and imported to STATA version 12 for analysis. Data were analyzed using descriptive and inferential statistics. Frequency distribution tables and histogram were used to descriptively analyze the data. Pearson chi-square and $p$ values were also used to test for associations between variables. The knowledge of the food vendors on food safety was the independent variable, while the food safety practices of the food vendors were dependent.

\section{Results and Discussion}

3.1. Demographic Data of Participants. The study comprised 340 street food vendors participating in the study $(100 \%$ response rate). The mean age of the participants was $35.47 \pm 10.39$ years. Their ages ranged from 15 to 62 years, and the majority of them (82.6\%) were between 20 and 49 years, as shown in Table 1 . Those below 20 years and above 49 years represented $6.8 \%$ and $10.6 \%$ of the total participants, respectively. Most of the food vendors (91\%) were females. More than half of the participants (53.2\%) had attained junior high school education. Sixty nine $(20.3 \%)$ had completed senior high school and only seven $(2.1 \%)$ had attained tertiary education. Those who had attained primary education and those without any formal education constituted $8.8 \%$ and $15.6 \%$ of the total participants, respectively, as indicated in Table 1 . Also, $85.88 \%$ of the participants were Christians, while the remaining $14.12 \%$ were Muslims. On marital status, $55.59 \%$ and $32.35 \%$ of the participants were, respectively, married and single. Others including those separated, divorce, cohabitation, and widow constituted $4.41 \%, 1.47 \%, 2.65 \%$, and $3.53 \%$, respectively. $52.06 \%$ (177) of the participants had $0-4$ years of working experience as food vendors, while only $3.24 \%$ (11) had 30-34 years of experience as indicated in Table 1. Also, 210 (61.76\%) had been trained by the district on food safety, while the remaining were never trained. However, $83.24 \%$ were having license for operation at the time of the study. And among these, only $25.09 \%$ had their licenses at the work place at the study time. The majority of the participants (66.82\%) work all day from morning to evening, while an insignificant $0.88 \%$ of them operate only in the afternoon.

3.2. Knowledge of Food Vendors on Food Safety. The mean food safety knowledge score of food vendors in the study was $78.35 \pm 9.33 \%$ and graded as good. The level of knowledge of the majority $(98.8 \%)$ of the participants was good, while only $1.2 \%$ had poor knowledge on food safety. The distribution of the food safety knowledge scores of the participants is presented in Figure 1.

\subsection{Association between Knowledge on Food Safety Based} on Sociodemographic Characteristics of Participants. Statistically significant differences in the food safety knowledge of food vendors were found on the basis of religion $\left(\chi^{2}=4.30 ; p\right.$ value $\left.\leq 0.038\right)$, training $\left(\chi^{2}=6.54 ; p\right.$ value $\leq 0.011)$, marital status $\left(\chi^{2}=35.15 ; p\right.$ value $\left.\leq 0.001\right)$, and license status $\left(\chi^{2}=9.84 ; p\right.$ value $\left.\leq 0.002\right)$ as indicated in Table 2. No statistical difference was found between the food safety knowledge of food vendors based on their education level $\left(\chi^{2}=4.28 ; p\right.$ value $\left.\leq 0.369\right)$, age group $\left(\chi^{2}=6.80 ; p\right.$ value $\leq 0.236)$, sex $\left(\chi^{2}=0.41 ; p\right.$ value $\left.\leq 0.524\right)$, working experience $\left(\chi^{2}=3.73 ; p\right.$ value $\left.\leq 0.589\right)$, and their operating time $\left(\chi^{2}=2.04 ; p<0.843\right)$ (see Table 2$)$. 
TABLE 1: Sociodemographic characteristics of participants.

\begin{tabular}{|c|c|c|}
\hline Variables & Frequency & Percentage (\%) \\
\hline \multicolumn{3}{|l|}{ Age group (years) } \\
\hline $10-19$ & 23 & 6.76 \\
\hline $20-29$ & 76 & 22.35 \\
\hline $30-39$ & 129 & 37.94 \\
\hline $40-49$ & 76 & 22.35 \\
\hline $50-59$ & 31 & 9.12 \\
\hline $60-69$ & 5 & 1.47 \\
\hline \multicolumn{3}{|l|}{ Sex } \\
\hline Male & 31 & 9.12 \\
\hline Female & 309 & 90.88 \\
\hline \multicolumn{3}{|l|}{ Education level } \\
\hline None & 53 & 15.59 \\
\hline Primary & 30 & 8.82 \\
\hline JHS & 181 & 53.24 \\
\hline SHS & 69 & 20.29 \\
\hline Tertiary & 7 & 2.06 \\
\hline \multicolumn{3}{|l|}{ Religion } \\
\hline Christian & 292 & 85.88 \\
\hline Islam & 48 & 14.12 \\
\hline \multicolumn{3}{|l|}{ Marital status } \\
\hline Single & 110 & 32.35 \\
\hline Married & 189 & 55.59 \\
\hline Separated & 15 & 4.41 \\
\hline Divorced & 5 & 1.47 \\
\hline Cohabitation & 9 & 2.65 \\
\hline Widow & 12 & 3.53 \\
\hline \multicolumn{3}{|l|}{ Work experience (years) } \\
\hline $0-4$ & 177 & 52.06 \\
\hline $5-9$ & 69 & 20.29 \\
\hline $10-14$ & 56 & 16.47 \\
\hline $15-19$ & 15 & 4.41 \\
\hline $20-24$ & 12 & 3.53 \\
\hline $30-34$ & 11 & 3.24 \\
\hline \multicolumn{3}{|l|}{ Operation time } \\
\hline Morning-evening & 226 & 66.47 \\
\hline Morning-afternoon & 63 & 18.53 \\
\hline Afternoon-evening & 22 & 6.47 \\
\hline Morning only & 15 & 4.41 \\
\hline Afternoon only & 3 & 0.88 \\
\hline Evening only & 11 & 3.24 \\
\hline \multicolumn{3}{|l|}{$\begin{array}{l}\text { Ever attended training by the } \\
\text { assembly }\end{array}$} \\
\hline No & 130 & 38.24 \\
\hline Yes & 210 & 61.76 \\
\hline \multicolumn{3}{|l|}{ Recent training attended } \\
\hline This year & 112 & 53.33 \\
\hline Last year & 66 & 31.43 \\
\hline Two years ago & 20 & 9.52 \\
\hline More than three years ago & 12 & 5.71 \\
\hline \multicolumn{3}{|l|}{ License for operation } \\
\hline No & 57 & 16.76 \\
\hline Yes & 283 & 83.24 \\
\hline \multicolumn{3}{|c|}{ License available at vending site } \\
\hline No & 212 & 74.91 \\
\hline Yes & 71 & 25.09 \\
\hline
\end{tabular}

Source: authors' construct (2019).

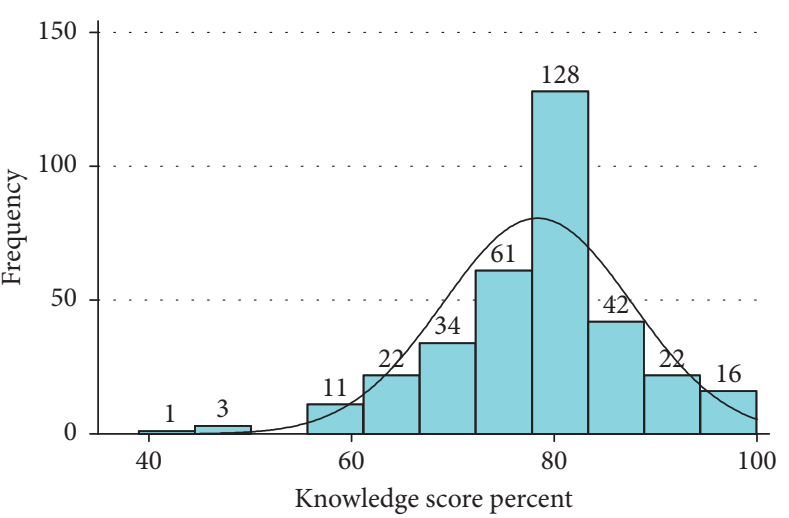

FIgURE 1: Distribution of food safety knowledge scores. Source: authors' construct (2019).

TABle 2: Association between knowledge on food safety based on sociodemographic characteristics.

\begin{tabular}{lcc}
\hline Variables & Chi-square $\left(\chi^{2}\right)$ & $p$ value \\
\hline Age group & 6.80 & 0.236 \\
Sex & 0.41 & 0.524 \\
Educational level & $\mathbf{4 . 2 8}$ & $\mathbf{0 . 3 6 9}$ \\
Training & $\mathbf{6 . 5 4}$ & $\mathbf{0 . 0 1 1 ^ { * }}$ \\
Religion & $\mathbf{4 . 3 0}$ & $\mathbf{0 . 0 3 8}^{*}$ \\
Marital status & $\mathbf{3 5 . 1 5}$ & $<\mathbf{0 . 0 0 1}^{*}$ \\
Working experience & 3.73 & 0.589 \\
Operating time & 2.04 & 0.843 \\
License & $\mathbf{9 . 8 4}$ & $\mathbf{0 . 0 0 2}^{*}$ \\
\hline
\end{tabular}

Source: authors' construct (2019).

3.4. Food-Handling Practices of Participants. The mean foodhandling score of food vendors during serving was $70.41 \pm 19.34 \%$ (Table 3 ). This score was graded as good. The majority of the food vendors (85.2\%) practiced good food handling during serving. Also, out of 340 food vendors, the majority of the food vendors (91.1\%) served food hot, $84.1 \%$ protected their food from flies, and $89.1 \%$ did not allow customers to make contact with food being served (see Table 3). The majority of the food vendors (56.4\%) did not handle food with their bare hands. It was observed that about 7 out of every 10 food vendors used the same hand to serve and collect money. Most food vendors used either plates (or bowls) or plain rubber for serving food $(92.8 \%$ and $96.8 \%$, respectively), while few vendors used disposable bowls (takeaway bowls) or newspaper for serving food $(7.1 \%$ and $2.9 \%$, respectively) (see Table 3 ).

3.5. Association between Food-Handling Practices and Sociodemographic Characteristics of Participants. There were no statistically significant differences in the food-handling practices of food vendors during serving on the basis of their age groups $\left(\chi^{2}=8.29 ; p\right.$ value $\left.\leq 0.141\right)$, sex $\left(\chi^{2}=0.09 ; p\right.$ value $\leq 0.766)$, knowledge on food safety $\left(\chi^{2}=0.34 ; p\right.$ value $\leq 0.559)$, level of education $\left(\chi^{2}=3.30 ; p\right.$ value $\left.\leq 0.508\right)$, 
TABLE 3: Food-handling practices of participants.

\begin{tabular}{|c|c|c|}
\hline Variable & Frequency & Percentage \\
\hline \multicolumn{3}{|l|}{ Handles food with bare hand } \\
\hline No & 192 & 56.47 \\
\hline Yes & 148 & 43.53 \\
\hline \multicolumn{3}{|l|}{ Customer makes contact with food } \\
\hline No & 303 & 89.12 \\
\hline Yes & 37 & 10.88 \\
\hline \multicolumn{3}{|c|}{$\begin{array}{l}\text { Uses same hand to serve and collect } \\
\text { money }\end{array}$} \\
\hline No & 91 & 26.76 \\
\hline Yes & 249 & 73.24 \\
\hline \multicolumn{3}{|l|}{ Food served hot } \\
\hline No & 32 & 9.41 \\
\hline Yes & 308 & 90.59 \\
\hline \multicolumn{3}{|l|}{ Food exposed to flies } \\
\hline No & 286 & 84.12 \\
\hline Yes & 54 & 15.88 \\
\hline \\
\hline & \multicolumn{2}{|c|}{ Plate } \\
\hline No & 21 & 6.18 \\
\hline Yes & 319 & 93.82 \\
\hline \multicolumn{3}{|l|}{ Plain rubber } \\
\hline No & 11 & 3.24 \\
\hline Yes & 329 & 96.76 \\
\hline \multicolumn{3}{|l|}{ Takeaway bowl } \\
\hline No & 316 & 92.94 \\
\hline Yes & 24 & 7.06 \\
\hline \multicolumn{3}{|l|}{ Newspaper } \\
\hline No & 330 & 97.06 \\
\hline Yes & 10 & 2.94 \\
\hline Mean food-handling score (\%) & \multicolumn{2}{|c|}{$70.41 \pm 19.34$} \\
\hline
\end{tabular}

Source: authors' construct (2019).

marital status $\left(\chi^{2}=5.54 ; p\right.$ value $\left.\leq 0.354\right)$, working experience $\left(\chi^{2}=5.74 ; p\right.$ value $\left.\leq 0.332\right)$, and operating time $\left(\chi^{2}=6.18 ; p\right.$ value $\left.\leq 0.289\right)$ (Table 4$)$. However, there was a statistically significant association between food-handling practices based on license $\left(\chi^{2}=9.16 ; p\right.$ value $\left.\leq 0.002\right)$ and association on the basis of training status $\left(\chi^{2}=10.16\right.$; $p$ value $\leq 0$. 001) (Table 4).

\section{Discussion}

The greater proportion of females who were street food vendors in this study reflects the sociocultural role of women in food preparation and serving in Ghana. Similar findings have been reported in Benin City, Nigeria [20], Ethiopia [21], and Uganda [6]. In countries such as Haiti [22] and Kenya [23], it was reported that street food vendors were predominantly males.

The average age of the food vendors was 35 years, and this is consistent with the mean age of street food vendors in Ghana [5]. However, Tessema et al. [21] reported a younger mean age (22.4 years) in Ethiopia. This discrepancy could be attributed to the desire of most Ghanaian youth to find better occupation, as being a street food vendor is seen as a least respected occupation among many Ghanaians. It is
TABLE 4: Association between food-handling practices and sociodemographic characteristics of participants.

\begin{tabular}{lcc}
\hline Variable & Chi-square $\left(\chi^{2}\right)$ & $p$ value \\
\hline Age groups & 8.29 & 0.141 \\
Sex & 0.09 & 0.766 \\
Educational level & 3.30 & 0.508 \\
Training & $\mathbf{1 0 . 1 6}$ & $<\mathbf{0 . 0 0 1}$ \\
Knowledge level & 0.34 & 0.559 \\
Marital status & 5.54 & 0.354 \\
Working experience & 5.74 & 0.332 \\
Operating time & 6.18 & 0.289 \\
License & $\mathbf{9 . 1 6}$ & $\mathbf{0 . 0 0 2}$ \\
\hline
\end{tabular}

Source: authors' construct (2019).

usually engaged as a temporal occupation or when there is no better alternative, hence waiting for longer periods before engaging as food vendors. Chukuezi [24] also reported a much older mean age (41.2 years) in Nigeria.

The study also showed that many of the food vendors have at least attained basic level of education, predominantly at the junior high school (JHS) level and many others at senior high school (SHS) level. Even though a good number of them (15.59\%) had no formal education, the findings reflected the increasing level of education of the Ghanaian population coupled with relatively low formal jobs for the teaming youth. The level of education of food vendors in Ghana may go higher in subsequent years due to the provision of free education up to SHS level by the government. Previously, studies by Apanga et al. [25] and Amaami et al. [1] reported low levels of education among street food vendors in Northern Ghana and Accra, respectively. However, Odonkor et al. [26] reported predominance of senior high-level education among street food vendors in Accra metropolis. This could be due to the fact that most educated individuals in Ghana like other developing countries seek jobs in the capital city where they are more likely to gain lucrative employment even in the informal sector (which includes the street food industry).

Education and training are major strategies for imparting knowledge and skills. From this study, the food safety knowledge of food vendors was good though the level of education of most of them was low below the tertiary level. Their knowledge was associated with training but not their education level. These findings reflect that of Samapundo et al. [22] in Haiti. Temeche et al. [27] on the other hand found no association between knowledge on food safety and education level or training in Ethiopia. However, Thanh [28], found an association between food safety knowledge of food vendors in Vietnam and their level of education and training. The findings show the relevance of the Ghana food safety policy direction which seeks to empower street food vendors on food safety through training. It also calls for the need to ensure the participation of food vendors in decision-making (policy formulation). The study showed that though most of the food vendors do not attain tertiary education, their knowledge on food safety is good and should therefore not be sidelined. 
Food-handling practices of food vendors during serving in this study were good. It was not associated with knowledge on food safety or level of education. It was however associated with training. This finding emphasizes the importance of training on influencing food-handling practices of food vendors. In places where proper handwashing with soap is rarely practiced before handling food, as found in Kenya by [29] where only $15 \%$ of the participants were washing their hands with soap before food handling, it becomes worrying when a significant proportion of participants in this study (73.24\% and $43.53 \%)$ used the same hand to handle money and food and with bare hands, respectively. Similar observation has been reported by Muyanja et al. [6] in Kampala and Jinja. This may increase the risk of food crosscontamination since money and bare hands have been found to harbor microorganisms [30]. Also, as indicated in the findings, $15.88 \%$ and $8.88 \%$ of the food vendors, respectively, exposed their foods to flies and serve cold foods. This poses serious health risk to consumers of such foods as they can easily be contaminated with germs and/or harbor different kind of disease-causing microorganisms. Plain rubber (polythene) may pose long-term health risk to individuals especially when used to serve hot and oily foods. Therefore, the discovery of majority of participants serving hot foods on plain rubber in this study calls for more research in this area of food safety, regular training of food vendors, and revised food safety-handling policies.

\section{Conclusion}

With women of an average age of 35 years dominating street food vending in the Ejisu-Juaben municipality in Ghana, their food safety knowledge and food-handling practices were generally good even though they had low level of education. The training programs organized by the municipal assembly for food vendors are of significant relevance to enhancing food vendors' knowledge on food safety and food-handling practices. Though encouraging, specific gaps in food-handling practices were discovered in this study and therefore calls for urgent action and further studies.

This study has revealed various gaps and clearly presented unsafety food-handling practices which are either overlooked or out of ignorance on the side of food vendors. This informs the municipal assemblies to revisit and intensify their training programs to include important but neglected food-handling practices.

The study therefore recommended that municipal assemblies should collaborate with international, governmental, and other nongovernmental organizations interested in street food safety to ensure effective implementation of food safety policies and organize more training programs. The municipal assemblies should make effort to secure regular funding and human resources support from these collaborations to strengthen and sustain the training programs by organizing regular training programs based on evidence from research. These collaborations can also be in the area of research to improve practices related to food safety.
Collaboration with media houses within a municipality to help advertise upcoming food safety training programs to promote patronage by food vendors is also relevant. Environmental health officers should also be equipped adequately with knowledge and skills through retraining to enable them to effectively facilitate training programs for food vendors. Information, education, and communication materials on food safety should also be readily available and easily accessible to food vendors.

\section{Data Availability}

The data used to support the findings of this study are available from the corresponding author upon request.

\section{Ethical Approval}

Ethical approval was obtained from the Committee of Human Research, Publication and Ethics of Kwame Nkrumah University of Science and Technology (reference number: CHRPE/AP/491/17). Ethical issues such as voluntariness, confidentiality, and anonymity stated on the consent forms were strictly complied with.

\section{Consent}

Informed consent was verbally obtained from every participant before the study. The researchers briefed the participants about the purpose and relevance of the study.

\section{Conflicts of Interest}

All authors declared no conflicts of interest.

\section{Acknowledgments}

This study acknowledged the acceptance and support of the Ejisu-Juaben Municipal executives for the study to be conducted.

\section{References}

[1] A. J. Amaami, D. Dominic, and D. Collins, "Factors associated with poor food safety compliance among street food vendors in the Techiman municipality of Ghana," African Journal of Food Science, vol. 11, no. 3, pp. 50-57, 2017.

[2] T. Njaya, "Operations of street food vendors and their impact on sustainable urban life in high density suburbs of Harare, in Zimbabwe," Asian Journal of Economic Modelling, vol. 2, no. 1, pp. 18-31, 2014.

[3] T. Mekasha, S. Neela, and D. Kumela, "Food safety knowledge, practice and attitude of food handlers in traditional hotels of Jimma Town, Southern Ethiopia," Annals Food Science and Technology, vol. 17, no. 2, pp. 507-517, 2016.

[4] I. Monney, D. Agyei, B. S. Ewoenam, C. Priscilla, and S. Nyaw, "Food hygiene and safety practices among street food vendors: an assessment of compliance, institutional and legislative framework in Ghana," Food and Public Health, vol. 4, no. 6, pp. 306-315, 2014.

[5] Food and Agriculture Organization of United Nations, "Street food in urban Ghana: a desk top review and analysis and 
recommendations from existing literature," 2016, http://www. fao.org/3/a-i5804e.pdf.

[6] C. Muyanja, L. Nayiga, N. Brenda, and G. Nasinyama, "Practices, knowledge and risk factors of street food vendors in Uganda," Food Control, vol. 22, no. 10, pp. 1551-1558, 2011.

[7] L. K. King, B. Awumbila, E. A. Canacoo, and S. Ofosu-Amaah, "An assessment of the safety of street foods in the Ga district, of Ghana; implications for the spread of zoonoses," Acta Tropica, vol. 76, no. 1, pp. 39-43, 2000.

[8] World Health Organization, "WHO's first ever global estimates of foodborne diseases," 2015, http://www.who.int/mediacentre/ news/releases/2015/foodborne-disease-estimates/en/.

[9] P. F. Ababio and P. Lovatt, "A review on food safety and food hygiene studies in Ghana," Food Control, vol. 47, pp. 92-97, 2015.

[10] P. Mensah, D. Yeboah-Manu, K. Owusu-Darko, and A. Ablordey, "Street foods in Accra, Ghana: how safe are they?" Bulletin of the World Health Organization, vol. 80, no. 7, pp. 546-554, 2002.

[11] P. K. Feglo and K. Sakyi, "Bacterial contamination of street vending food in Kumasi, Ghana," Journal of Medical and Biomedical Sciences, vol. 1, no. 1, pp. 1-8, 2012.

[12] C. P. d. Sousa, "The impact of food manufacturing practices on food borne diseases," Brazilian Archives of Biology and Technology, vol. 51, no. 4, pp. 615-623, 2008.

[13] A. Sylvester, "Ensuring food hygiene and safety in Ghana: a legal perspective," International Journal of Humanities and Social Sciences, vol. 8, no. 6, pp. 67-71, 2018.

[14] E. Donkor, B. Kayang, J. Quaye, and M. Akyeh, “Application of the WHO keys of safer food to improve food handling practices of food vendors in a poor resource community in Ghana," International Journal of Environmental Research and Public Health, vol. 6, no. 11, pp. 2833-2842, 2009.

[15] J. B. Forkuor, K. O. Akuoko, and E. Henry, Effective and Inclusive Regulation of Street Foods in Kumasi: Promoting Food Safety, Kwame Nkrumah University of Science and Technology, Kumasi, Ghana, 2017, http://dfcentre.com/wp-content/.../ 2017-03-27_11-P21-GHA-Kwasi-Ohene-Yankyera.pdf.

[16] Ghana Statistical Service, "2010 population and housing census: ejisu-juaben municipality,” 2014, http://www.statsghana.gov.gh/ docfiles/2010_District.../Ejisu-Juaben\%20Municipality.pdf.

[17] Ejisu-Juaben Municipal Assembly, "Annual progress report for 2013," 2014, https://s3.amazonaws.com/ndpc-static/ CACHES/.../AR-Ejisu+Juaben_+2014_APR.pd.

[18] Pennsylvania State University, "Estimating a proportion for a small, finite population," 2017, https://onlinecourses.science. psu.edu/stat414/node/264.

[19] World Health Organization, Essential Safety Requirements for Street-Vended Foods (No. WHO/FNU/FOS/96.7 Rev1), World Health Organization, Geneva, Switerzland, 1996.

[20] P. W. Okojie and E. C. Isah, "Sanitary conditions of food vending sites and food handling practices of street food vendors in Benin city, Nigeria: implication for food hygiene and safety," Journal of Environmental and Public Health, vol. 2014, Article ID: 701316, 6 pages, 2014.

[21] A. G. Tessema, K. A. Gelaye, and D. H. Chercos, "Factors affecting food handling Practices among food handlers of Dangila town food and drink establishments, north west Ethiopia," BMC Public Health, vol. 14, no. 1, p. 571, 2014.

[22] S. Samapundo, R. Climat, R. Xhaferi, and F. Devlieghere, "Food safety knowledge, attitudes and practices of street food vendors and consumers in Port-au-Prince, Haiti," Food Control, vol. 50, pp. 457-466, 2015.

[23] O. K. Muinde and E. Kuria, "Hygienic and sanitary practices of vendors of street food in nairobi, Kenya," Africa Journal of
Food, Agriculture, Nutrition and Development, vol. 5, no. 1, 2005.

[24] C. O. Chukuezi, "Food safety and hygienic practices of street food vendors in Owerri, Nigeria," Studies in Sociology of Science, vol. 1, no. 1, p. 50, 2010.

[25] S. Apanga, J. Addah, and D. R. Sey, "Food safety knowledge and practice of street food vendors in rural northern Ghana," Food and Public Health, vol. 4, no. 3, pp. 99-103, 2014.

[26] S. T. Odonkor, T. Adom, R. Boatin, D. Bansa, and C. J. Odonkor, "Evaluation of hygiene practices among street food vendors in Accra metropolis, Ghana," Elixir Food Science, vol. 41, pp. 5807-5811, 2011.

[27] M. Temeche, S. Neela, and K. Dibaba, "Food safety practices and attitude of food handlers in traditional hotels of Jimma town, Southern Ethiopia," Annals. Food Science Technology, vol. 17, no. 2, 2016.

[28] T. N. C. Thanh, "Food safety behavior, attitudes and practices of street food vendors and consumers in Vietnam," 2015, http://lib.ugent.be/fulltxt/RUG01/002/217/245/ RUG01-002217245_2015_0001_AC.pdf.

[29] W. P. Schmidt, R. Aunger, Y. Coombes et al., "Determinants of handwashing practices in Kenya: the role of media exposure, poverty and infrastructure," Tropical Medicine \& International Health, vol. 14, no. 12, pp. 1534-1541, 2009.

[30] P. Luure, W. Asare, S. Cobbina, A. Duwiejuah, and M. Nkoom, "Microbial contamination of Ghanaian cedi notes from traders of the tamale central market, Ghana," British Microbiology Research Journal, vol. 5, no. 2, pp. 139-145, 2015. 